\title{
Factorial design applied to the optimization of lipid composition of topical antiherpetic nanoemulsions containing isoflavone genistein
}

This article was published in the following Dove Press journal:

International Journal of Nanomedicine

9 October 2014

Number of times this article has been viewed

\author{
Débora Fretes Argenta' \\ Cristiane Bastos de Mattos' \\ Fabíola Dallarosa Misturini' \\ Leticia Scherer Koester' \\ Valquiria Linck Bassani' \\ Cláudia Maria Oliveira \\ Simões ${ }^{2}$ \\ Helder Ferreira Teixeira' \\ 'Programa de Pós-graduação \\ em Ciências Farmacêuticas da \\ Universidade Federal do Rio \\ Grande do Sul, Porto Alegre, Brazil; \\ ${ }^{2}$ Programa de Pós-graduação em \\ Farmácia da Universidade Federal de \\ Santa Catarina, Florianópolis, Brazil
}

Correspondence: Helder Ferreira

Teixeira

Programa de Pós-graduação em Ciências Farmacêuticas da Universidade Federal do Rio Grande do Sul (UFRGS),

Av lpiranga 2752, 90610-000 Porto

Alegre, Brazil

Tel +55 5I 3308 55I4

Email helderteixeira@ufrgsbr

\begin{abstract}
The aim of this study was to optimize topical nanoemulsions containing genistein, by means of a $2^{3}$ full factorial design based on physicochemical properties and skin retention. The experimental arrangement was constructed using oil type (isopropyl myristate or castor oil), phospholipid type (distearoylphosphatidylcholine [DSPC] or dioleylphosphaditylcholine [DOPC]), and ionic cosurfactant type (oleic acid or oleylamine) as independent variables. The analysis of variance showed effect of third order for particle size, polydispersity index, and skin retention of genistein. Nanoemulsions composed of isopropyl myristate/DOPC/oleylamine showed the smallest diameter and highest genistein amount in porcine ear skin whereas the formulation composed of isopropyl myristate/DSPC/oleylamine exhibited the lowest polydispersity index. Thus, these two formulations were selected for further studies. The formulations presented positive $\zeta$ potential values $(>25 \mathrm{mV}$ ) and genistein content close to $100 \%$ (at $1 \mathrm{mg} / \mathrm{mL}$ ). The incorporation of genistein in nanoemulsions significantly increased the retention of this isoflavone in epidermis and dermis, especially when the formulation composed by isopropyl myristate/DOPC/oleylamine was used. These results were supported by confocal images. Such formulations exhibited antiherpetic activity in vitro against herpes simplex virus 1 (strain KOS) and herpes simplex virus 22 (strain 333). Taken together, the results show that the genistein-loaded nanoemulsions developed in this study are promising options in herpes treatment.
\end{abstract}

Keywords: skin retention, antiherpetic activity, phospholipids, cationic nanoemulsions

\section{Introduction}

Herpes simplex virus (HSV) types 1 and 2 cause various human diseases, such as gingivostomatitis, herpes labialis, meningitis, and ocular and genital infections. ${ }^{1}$ These viruses are able to establish and maintain latent infections that can be reactivated by different stimuli, such as stress, ultraviolet light, hormones, and immunosuppression. ${ }^{2}$ Several drugs are currently available for the treatment of HSV infections. However, the emergence of viral strains resistant to available nucleoside analog drugs has stimulated the search for novel antiherpetic drugs. ${ }^{3}$

Studies exploring the evaluation of the antiherpetic activity of natural compounds, such as flavonoids, have been described. ${ }^{4-6}$ For instance, Lyu et al evaluated the antiherpetic action of five different classes of flavonoids. ${ }^{7}$ Among the flavonoids tested, genistein - the main soybean isoflavone - showed an important inhibition of virusinduced cytopathic effect. The antiviral activity of genistein has been attributed to its tyrosine kinase-inhibitor effect. ${ }^{8}$ This kind of inhibition is one of the mechanisms responsible for reducing the infectivity of several viruses, including HSV. ${ }^{9}$ In vitro experiments suggested that genistein reduced the HSV-1 replication by specifically inhibiting tyrosine residues' phosphorylation of HSV-1 polypeptides. ${ }^{10}$ 
In the topical treatment of herpes labialis, the bioactive compounds need to reach the stratum basale of the epidermis since this is the main site for HSV replication. ${ }^{11}$ However, human skin is an efficient and selective barrier against the entrance of chemical/biological agents, and therapeutic agents must overcome its integrity, which mainly resides in the outermost layer of skin, the stratum corneum. This layer contains relatively low concentrations of water, being composed of corneocytes surrounded by lipids, which are arranged in highly organized lamellar bilayers. ${ }^{12,13}$ Thus, several research articles have focused on the evaluation of methods to overcome this resistance and increase stratum corneum permeability, thereby improving drug diffusion through the skin.

Various factors may play a role in the skin penetration of active compounds, including the influence of drug partitioning and its ability to diffuse through the skin layers. Skin permeation enhancement can be achieved by altering the thermodynamic properties of the drug and/or changing the barrier properties of the stratum corneum. ${ }^{14} \mathrm{~A}$ longstanding pharmaceutical approach to overcome this barrier effect is the use of penetration enhancers. Different chemicals have been used in this field, such as oils, fatty acids, and surfactants. These compounds may act through different mechanisms, including exerting different levels of interactions with stratum corneum cells, affecting cohesion between corneocytes, and modifying the resistance of the lipid bilayer. ${ }^{15,16}$ The use of penetration enhancers in the design of colloidal carriers has been a useful strategy to improve the skin's percutaneous absorption of drugs. ${ }^{17-19}$ Such carriers could increase the skin's permeation rate and enhance the topical effect due to the large surface area and low surface tension of these systems. ${ }^{20-22}$

The development of nanoemulsions aimed to improve the skin delivery of drugs and has attracted much interest. Nanoemulsions are composed of vegetal, synthetic, or semisynthetic oils that are very often stabilized by phospholipids as surfactant. Phospholipids are endogenous components of the human skin that have been extensively used as skin penetration enhancers, due to their high biocompatibility. ${ }^{23}$ The incorporation of cosurfactants that may improve the permeation/retention of compounds through the skin has also been investigated. For instance, positively-charged surfactants may also have an effect on the permeation/retention of drugs, due to the possibility of increasing interaction with epithelial cells, which carry a negative charge in the outer cell membranes. Thus, different variables may have an effect on permeation. A factorial design can be used for planning formulation studies, providing maximum information with a small number of experiments. ${ }^{24}$ Such design could provide a better combination of the formulation's composition, and the skin permeation can be used as a response.

Previous studies by Silva et al and de Vargas et al have showed the feasibility of incorporating the isoflavone genistein into topical nanoemulsions. ${ }^{25,26}$ Following up on these results, here we applied a $2^{3}$ factorial design to optimize the composition of topical nanoemulsions containing genistein. Our first aim was to evaluate simultaneously the effect of different oils (isopropyl myristate [IM] or castor oil [CO]), surfactants (dioleylphosphaditylcholine [DOPC] or distearoylphosphatidylcholine [DSPC]), and cosurfactants (oleic acid [OA] or oleylamine [OLA]) on the physicochemical properties of nanoemulsions and the retention of genistein into the porcine ear skin. Next, the distribution of genistein in skin layers was investigated for the optimized formulations, as well as their in vitro antiherpetic activity (anti-HSV-1 and anti-HSV-2).

\section{Materials and methods Materials}

$\mathrm{CO}$, IM, genistein, OLA, OA, and the dye Nile Red were purchased from Sigma-Aldrich Corp (St Louis, MO, USA). Distearoylphosphocholine (DSPC) and dioleylphosphocholine (DOPC) were obtained from Lipoid GmbH (Ludwigshafen, Germany). Polysorbate 80 was supplied by Vetec Quimica Fina Ltda. (Duque de Caxias, Brazil). Methanol and trifluoroacetic acid were purchased from Merck KGaA (Darmstadt, Germany). Ultrapure water was obtained from a Milli- $Q^{\circledR}$ Plus apparatus (Merck Millipore, Billerica, MA, USA). Pig ears were generously donated by Ouro do Sul - Cooperativa dos Suinocultores do Caí Superior Ltda. (Harmonia, Brazil).

\section{High-performance liquid chromatography analysis}

The quantification of genistein in different samples (oils, formulations, and skin layers) was assessed by high-performance liquid chromatography (HPLC) using previously validated conditions. ${ }^{26}$ In brief, HPLC apparatus consisted of a Shimadzu LC-10A system (Kyoto, Japan) equipped with a model LC-20AT pump, a SPD-20AV ultraviolet-visible variable wavelength detector (set at $270 \mathrm{~nm}$ ), a DGU-20A5 degasser, a CBM-20A system controller, and a SIL-20A injection valve with a $100 \mu \mathrm{L}$ loop. Genistein was analyzed using a Shim-pack CLC-ODS (M) RP-18 column ( 5 mm, 250×4 mm inner diameter). The mobile phase consisted of a mixture of methanol/water, with $0.1 \%$ trifluoracetic acid $(70: 30, \mathrm{v} / \mathrm{v})$ in isocratic flow at a flow rate of $1.2 \mathrm{~mL} / \mathrm{min}$. 


\section{Determination of genistein solubility in oils}

The solubility of genistein was determined by adding an excess amount of this isoflavone to IM and CO. The mixtures were kept under moderate magnetic stirring for 24 hours at room temperature to reach equilibrium. After, the samples were centrifuged at 15,000 rpm for 15 minutes, and an aliquot of the supernatant of each sample was weighed and diluted with methanol. Genistein content was assayed by HPLC as described above. The experiments were performed in triplicate.

\section{Experimental factorial design}

Formulations were obtained by the combination of different oils (X1), phospholipids (X2), and ionic surfactants (X3), according to a qualitative $2^{3}$ full factorial design (Table 1). The final composition of the formulations $(\mathrm{w} / \mathrm{w})$ was $8.0 \%$ of the oil (IM or CO), $2.0 \%$ of phospholipid (DOPC or DSPC), $0.05 \%$ of ionic surfactant (OA or OLA), and $1.0 \%$ of nonionic surfactant, polysorbate 80 , and Milli-Q water up to $100 \%$. Eight different formulations (NE1-NE8) were prepared in triplicate. Statistical analysis was performed using the Minitab $^{\circledR}$ software at a significance level of $P<0.05$.

Nanoemulsions were prepared by spontaneous emulsification. This method consists of injecting an organic phase containing oil core components into the water phase, under magnetic stirring. Subsequently, the organic solvent (ethanol) was removed by evaporation under reduced pressure, at $40^{\circ} \mathrm{C}-45^{\circ} \mathrm{C}$. The final $\mathrm{pH}$ of formulations was adjusted to values ranging from 5.0 to 6.0 . A control solution was prepared at $1 \mathrm{mg} / \mathrm{mL}$ of genistein in propylene glycol.

The dependent variables related to the physicochemical properties of formulations were the mean droplet size, the polydispersity index, the $\zeta$ potential, and also, the genistein content. The total amount of genistein retained in the whole skin was also used as an additional dependent variable. The experimental conditions used to evaluate these variables are described in the "Characterization of the nanoemulsions" and "Skin permeation/retention studies" sections.

Table I Independent factors and their levels

\begin{tabular}{llll}
\hline Factors & & Level & \\
\cline { 3 - 4 } & & Low & High \\
& & level $(-I)$ & level $(+I)$ \\
\hline X1 & Oil & IM & CO \\
X2 & Phospholipid & DSPC & DOPC \\
X3 & lonic cosurfactant & OLA & OA \\
\hline
\end{tabular}

Abbreviations: CO, castor oil; IM, isopropyl myristate; DOPC, dioleylphosphaditylcholine; DSPC, distearoylphosphatidylcholine; OA, oleic acid; OLA, oleylamine.

\section{Characterization of the nanoemulsions}

The droplet size and the $\zeta$ potential of the nanoemulsions were determined by photon correlation spectroscopy and electrophoretic mobility, respectively (3000HS Zetasizer; Malvern Instruments, Malvern, England). The samples were diluted in water, for size, or in $1 \mathrm{mM} \mathrm{NaCl}$ solution, for $\zeta$ potential measurements. Morphological examination was performed by means of transmission electron microscopy (TEM). The formulations were diluted at a 1:10 ratio, obtaining an oil phase concentration equal to $1 \%$. Specimens for TEM viewing were prepared by mixing samples with one droplet of $2 \%(\mathrm{w} / \mathrm{v})$ uranyl acetate solution. The samples were then adsorbed to the 200 mesh Formvar-coated copper grids, left to dry, and examined by TEM (JEM-1200 ExII; JEOL Ltd., Tokyo, Japan).

The total genistein content was determined after the dilution of formulations in methanol. To estimate the genistein association, nanoemulsions were directly added to ultrafiltration membranes (100,000 Da cutoff, Ultrafree; Merck Millipore) and centrifuged at 15,000 rpm for 15 minutes. The association efficiency (\%) was estimated by the difference between the total and free-genistein concentrations.

\section{Skin permeation/retention studies}

Porcine ears were obtained from a local slaughterhouse. The ears were withdrawn from the animals before the scalding procedure, cleaned, and the full-thickness skin was excised from the outer region of the ear with a scalpel. After the removal of subcutaneous fat, the skin was wrapped in aluminum foil and stored at $-20^{\circ} \mathrm{C}$ for a maximum time period of 1 month. Genistein permeation/retention was assessed using Franz-type diffusion cells, which presented a surface area for diffusion of $1.77 \mathrm{~cm}^{2}$ and a receptor volume of $10.0 \mathrm{~mL}$. Porcine ear skin with a thickness about 0.6 to $0.9 \mathrm{~mm}$ was set between the donor and the receptor compartments, with the dermal side facing downward into the receptor medium. Experiments were performed in sink conditions, due to the presence of $30 \%$ ethanol in phosphate-buffered saline in the receptor phase. The bathing solution was kept under a controlled temperature $\left(32^{\circ} \mathrm{C}\right)$. Approximately $500 \mu \mathrm{L}$ of each nanoemulsion were placed in the donor compartment. After 8 hours, samples of the receptor fluids were withdrawn from the compartment, and the skin was removed from the cell and cleaned using a cotton swab embedded with Milli-Q water. The genistein content was assessed by HPLC, as described in the "High-performance liquid chromatography analysis" section, in the receptor fluid and in the whole skin, after discarding the first tape strip. 
To evaluate the distribution of genistein into the skin layers from selected formulations (NE1 and NE3), genistein retention was determined in the stratum corneum, epidermis, and dermis. Briefly, the first stripped tape was discarded, while the following 15 tapes were used for genistein assay (stratum corneum). Next, the epidermis was separated from the dermis using a scalpel. The dermis was perforated into tiny pieces, and the layers were placed in the test tube. Results were expressed as mean \pm standard deviation of genistein retained per unit of area $\left(\mu \mathrm{g} / \mathrm{cm}^{2}\right)$ from five experiments.

\section{Histological and confocal fluorescence microscopy studies}

For histological studies, the skin cuts were cleaned with a cotton swab and immersed in formaldehyde solution (at 37\%). Subsequently, the cuts were dehydrated, embedded in paraffin, and sectioned, with a thickness of $6 \mu \mathrm{m}$. The skin tissue specimens, after staining with hematoxylin and eosin, were photographed by optical microscopy. For confocal fluorescence experiments, a fluorescent dye, Nile Red, was added during the preparation of nanoemulsions by a spontaneous emulsification process. Formulations NE1 and NE3 were prepared containing this fluorescent dye at a final concentration of $0.05 \%$ (previously solubilized in ethanol). Approximately $500 \mu \mathrm{L}$ of each fluorescent nanoemulsion was placed in the donor compartment, and the permeation/retention study was performed under the same experimental conditions described in the "Skin permeation/retention studies" section. After 8 hours, the skin cuts were cleaned and mounted with TissueTek $^{\circledR}$ O.C.T. ${ }^{\mathrm{TM}}$ (Sakura Finetechnical Co., Ltd., Tokyo, Japan) onto a metal sample holder and frozen at $-20^{\circ} \mathrm{C}$. Vertical slices of skin cuts of $40 \mu \mathrm{m}$ thickness were obtained with a cryostat (CM 1,850; Leica Microsystems, Wetzlar, Germany), and the slides were evaluated using a confocal microscopic Olympus FluoView ${ }^{\mathrm{TM}}$ 1,000 (Olympus Corporation, Tokyo, Japan), with a helium-neon red laser exciting at $559 \mathrm{~nm}$. The images were taken at a tenfold magnification.

\section{In vitro evaluation of antiherpetic activity of genistein-loaded nanoemulsions \\ Cells and viruses}

The cell lines used were Vero (CCL81; American Type Culture Collection, Manassas, VA, USA) and green monkey kidney (GMK) AH1 (Department of Clinical Virology, Gothenburg University, Gothenburg, Sweden). They were grown in Eagle's minimum essential medium (MEM) (Cultilab, Campinas, Brazil) supplemented with $10 \%$ fetal bovine serum (Cultilab) and maintained at $37^{\circ} \mathrm{C}$ in a humidified
$5 \% \mathrm{CO}_{2}$ atmosphere chamber. The HSV-1 (KOS strain) (Faculty of Pharmacy, University of Rennes, Rennes, France) and HSV-2 (333 strain) (Department of Clinical Virology, Gothenburg University) were propagated in Vero and GMK AH1 cells, respectively. Stock viruses were prepared, titrated based on plaque-forming units, counted by plaque assay, as previously described, and stored at $-80^{\circ} \mathrm{C} .{ }^{27}$

\section{Cytotoxicity assay}

The cytotoxicity of genistein (dissolved in $1.0 \%$ dimethylsulfoxide) and the nanoemulsions was determined by sulforhodamine B assay. ${ }^{28}$ Briefly, the cells were trypsinized, seeded into 96 -well microplates, and allowed to adhere for 24 hours, at $37^{\circ} \mathrm{C}$ in a $5 \% \mathrm{CO}_{2}$ atmosphere chamber. Afterwards, different concentrations of the samples were dispensed into the wells and incubated for 48 hours. The cells were stained with sulforhodamine B, and absorbance was measured at $510 \mathrm{~nm}$ using a microplate reader, and for each sample, the concentration at which cell viability was reduced by $50 \%\left(\mathrm{CC}_{50}\right)$ was calculated, comparing with the untreated controls.

\section{Antiherpetic activity}

The potential antiherpetic activity of genistein and genisteinloaded nanoemulsions was evaluated by the plaque number reduction assay, as previously described by Silva et al. ${ }^{29}$ Confluent monolayers of Vero or GMK AH1 cells were infected with 100 plaque-forming units per well of HSV-1 (KOS strain) or HSV-2 (strain 333), respectively, for 1 hour at $37^{\circ} \mathrm{C}$. After, the cells were washed with phosphatebuffered saline and overlaid with agarose gel $(0.6 \%)$ in the presence or absence of different concentrations of genistein or genistein-loaded nanoemulsions, and the plates were incubated for 48 hours. Cells were then fixed and stained with naphthol blue-black, and viral plaques were counted. The $\mathrm{IC}_{50}$ of each sample was defined as the concentration that inhibited $50 \%$ of viral plaque number when compared with untreated controls.

The $\mathrm{IC}_{50}$ and $\mathrm{CC}_{50}$ values were estimated by linear regression of the concentration-response curves generated from the obtained data. The selectivity index $\left(\mathrm{CC}_{50} / \mathrm{IC}_{50}\right)$ of each tested sample also was determined. All experiments were performed in triplicate.

\section{Statistical analysis}

The mean and standard deviations were calculated for all experiments. The statistical analysis was according to paired $t$-test or analysis of variance $(P<0.05)$ in a factorial experimental design, using Minitab 15 software. 


\section{Results}

\section{Solubility determination in tested oils}

Genistein solubility in the oil cores used for the preparation of nanoemulsions was estimated by adding an excess of this isoflavonoid in IM or $\mathrm{CO}$. Genistein was much more soluble in $\mathrm{CO}(3.32 \pm 0.25 \mathrm{mg} / \mathrm{g})$ than in IM $(0.34 \pm 0.01 \mathrm{mg} / \mathrm{g})$.

\section{Nanoemulsion optimization by factorial design}

Table 2 shows the experimental arrangement based on the $2^{3}$ full factorial design as well as the measured responses (droplet size, polydispersity index, $\zeta$ potential, genistein content, and skin genistein retention) for the eight formulations obtained by means of spontaneous emulsification. Analysis of variance of responses was performed (Table 3). For mean droplet size (Y1), polydispersity index (Y2), and genistein retention (Y5), the analysis of variance for these responses showed statistical significance for the effects of third-order interactions. The mean droplet size varied, from approximately $160 \mathrm{~nm}$ to $420 \mathrm{~nm}$. The combination of X1, $\mathrm{X} 2$, and $\mathrm{X} 3$ over $\mathrm{Y} 1$ response allowed the selection of NE3 (IM/DOPC/OLA) due to the lowest droplet size $(161 \pm 6 \mathrm{~nm})$. This droplet size value was significantly different from other all-lipid combinations. The CO/DSPC/OA (NE6) combination led to the highest mean droplet size $(426 \pm 82 \mathrm{~nm})$. With regard to the polydispersity index, the combination of IM/ DSPC/OLA (NE1) exhibited the lowest value (0.07 \pm 0.02$)$, which was significantly different from the other formulations. As a general rule, formulations presented a polydispersity index lower than 0.3 , except for NE6 (CO/DOPC/OLA), for which the highest value, of $0.58 \pm 0.08$, was observed. Finally, concerning the skin retention of genistein, the values ranged from $0.56 \mu \mathrm{g} / \mathrm{cm}^{2}$ to $1.86 \mu \mathrm{g} / \mathrm{cm}^{2}$. The use of IM (NE1 to NE4) led to a higher retention in the skin; however, NE3
(IM/DOPC/OLA) presented the highest skin retention of genistein $\left(1.86 \pm 0.32 \mu \mathrm{g} / \mathrm{cm}^{2}\right)$. The value was significantly lower for NE1, NE2, and NE4, without significance among them. Considering the effect of two-way interaction over the Y4 response (genistein content), NE5 and NE6 presented no statistical differences between them $(P=0.05)$, and NE6 presented the lowest content of genistein $(P<0.05)$ in relation to the other nanoemulsions. $\zeta$ potential response $(\mathrm{Y} 3)$ was significantly affected by oil type and ionic surfactant but not by interactions among them. The NE3 and NE7 nanoemulsions showed higher values $(P<0.05)$ in modulus for $\zeta$ potential response when compared with the other formulations (higher than $30 \mathrm{mV}$ ).

\section{TEM imaging of selected nanoemulsions}

The morphology of the NE1 and NE3 nanoemulsions can be seen in Figure 1. The TEM images showed the typical appearance of oil-water nanoemulsions, with oil droplets displaying a size of close to $150-250 \mathrm{~nm}$.

\section{Genistein distribution into skin layers from selected nanoemulsions}

Figure 2 shows the amount of genistein retained from the formulations, in the porcine ear skin layers. Regardless of the composition, genistein was detected in all layers. A lower amount of genistein was detected in the stratum corneum from nanoemulsions in comparison with the control propylene glycol solution. The incorporation of genistein into nanoemulsions significantly increased the retention of this isoflavone in the epidermis and dermis $(P<0.05)$. In addition, the formulation composed by IM/DOPC/OLA (NE3) led to a significantly higher amount $(P<0.05)$ of genistein in the dermis in comparison with those composed by IM/DSPC/OLA (NE1). Following 8 hours of permeation/retention, genistein

Table 2 Experimental arrangement based on the $2^{3}$ full factorial design and measured responses for eight experiment runs

\begin{tabular}{|c|c|c|c|c|c|c|c|c|}
\hline \multirow[t]{2}{*}{ Code } & \multirow{2}{*}{\multicolumn{3}{|c|}{$\begin{array}{l}\text { Experimental } \\
\text { arrangement }\end{array}$}} & \multirow{2}{*}{$\begin{array}{l}\text { YI } \\
Z \text {-ave } \\
(\mathbf{n m}) \pm \text { SD }\end{array}$} & \multirow{2}{*}{$\frac{\mathbf{Y} 2}{\mathbf{P I} \pm \mathrm{SD}}$} & \multirow{2}{*}{$\begin{array}{l}\text { Y3 } \\
\zeta \text { potential } \\
(\mathrm{mV}) \pm \mathrm{SD}\end{array}$} & \multirow{2}{*}{$\begin{array}{l}\text { Y4 } \\
\text { GEN content } \\
(\mathrm{mg} / \mathrm{mL}) \pm \text { SD }\end{array}$} & \multirow{2}{*}{$\begin{array}{l}\text { Y5 } \\
\text { GEN retained } \\
\left(\mu \mathrm{g} / \mathrm{cm}^{2}\right) \pm \text { SD }\end{array}$} \\
\hline & & & & & & & & \\
\hline NEI & $\mathrm{IM}$ & DSPC & OLA & $213.60 \pm 18.07$ & $0.07 \pm 0.02 *$ & $+25.20 \pm 10.85$ & $0.96 \pm 0.04 I$ & $I .4 I \pm 0.08$ \\
\hline NE2 & IM & DSPC & $O A$ & $236.90 \pm 19.27$ & $0.17 \pm 0.04$ & $-17.95 \pm 02.59$ & $0.94 \pm 0.047$ & $1.13 \pm 0.16$ \\
\hline NE3 & IM & DOPC & OLA & $161.19 \pm 06.64 *$ & $0.24 \pm 0.01$ & $+32.92 \pm 04.91$ & $0.95 \pm 0.042$ & $1.86 \pm 0.32 *$ \\
\hline NE4 & IM & DOPC & OA & $287.79 \pm 33.70$ & $0.30 \pm 0.04$ & $-|8.35 \pm 07.6|$ & $0.97 \pm 0.013$ & $1.06 \pm 0.10$ \\
\hline NE5 & $\mathrm{CO}$ & DSPC & OLA & $225.40 \pm 17.23$ & $0.19 \pm 0.02$ & $+23.97 \pm 03.19$ & $0.83 \pm 0.049 *$ & $0.90 \pm 0.20$ \\
\hline NE6 & $\mathrm{CO}$ & DSPC & OA & $426.40 \pm 82.94$ & $0.58 \pm 0.08$ & $-15.63 \pm 05.44$ & $0.80 \pm 0.06 I^{*}$ & $0.65 \pm 0.10$ \\
\hline NE7 & $\mathrm{CO}$ & DOPC & OLA & $190.82 \pm 03.70$ & $0.14 \pm 0.03$ & $+36.00 \pm 04.90$ & $0.97 \pm 0.048$ & $0.8 I \pm 0.12$ \\
\hline NE8 & $\mathrm{CO}$ & DOPC & $\mathrm{OA}$ & $219.02 \pm 20.68$ & $0.13 \pm 0.03$ & $-19.13 \pm 04.83$ & $0.97 \pm 0.044$ & $0.56 \pm 0.08$ \\
\hline
\end{tabular}

Note: *Significantly different $(P<0.05)$

Abbreviations: CO, castor oil; DOPC, dioleylphosphaditylcholine; DSPC, distearoylphosphatidylcholine; GEN, genistein; IM, isopropyl myristate; NE, nanoemulsion; OLA, oleylamine; OA, oleic acid; PI, polydispersity index; SD, standard deviation; Z-ave, droplet size. 
Table 3 The analysis of variance for responses

\begin{tabular}{llll}
\hline Responses & \multicolumn{2}{l}{ P-values } & \\
\cline { 2 - 4 } & $\begin{array}{l}\text { Main } \\
\text { effects }\end{array}$ & $\begin{array}{l}\text { Two-way } \\
\text { interactions }\end{array}$ & $\begin{array}{l}\text { Three-way } \\
\text { interactions }\end{array}$ \\
\hline Particle size (YI) & $<0.00 \mathrm{I}$ & 0.003 & $<0.00 \mathrm{I}$ \\
Polydispersity index (Y2) & $<0.00 \mathrm{I}$ & $<0.00 \mathrm{I}$ & $<0.00 \mathrm{I}$ \\
Zeta potential (Y3) & $0.00 \mathrm{I}$ & $0.38 \mathrm{I}$ & 0.898 \\
Genistein content (Y4) & $<0.00 \mathrm{I}$ & $0.01 \mathrm{I}$ & 0.898 \\
Skin retention (Y5) & $<0.00 \mathrm{I}$ & 0.028 & $0.00 \mathrm{I}$ \\
\hline
\end{tabular}

content was below the methods lower limit of quantification $(<0.1 \mu \mathrm{g} / \mathrm{mL})$ for both NE1 and NE3.

\section{Skin distribution of the dye Nile Red from selected formulations}

Figure 3 shows a photomicrograph panel of porcine ear skin colored by hematoxylin/eosin, of untreated skin (Figure $3 \mathrm{~A})$ or after 8 hours of the permeation/retention study for NE1 (Figure 3B) and NE3 (Figure 3C). Images showed the cells' nuclei stained in blue and the other components stained in red. Regardless of the treatment (NE1 and NE3), the treated skin maintained a structure similar to untreated skin (Figure 3A), presenting stratum corneum with little detachment, a well-defined nucleus and cytoplasm without vacuoles or lyses, absence of intraepidermal clefts, and dermal-epidermal junction without separation of the two layers. In similar experimental conditions, confocal images of vertical skin sections of $40 \mu \mathrm{m}$ thickness were performed (Figure 3D-F). The images revealed that the Nile Red dye was mainly located in the stratum corneum when this fluorescent dye was dispersed in propylene glycol. Fluorescence was distributed throughout the skin layers (stratum corneum, viable epidermis, and dermis) when this dye was incorporated into the nanoemulsions. The fluorescence intensity seems to be higher after nanoemulsion application when compared with the control solution.

\section{Antiherpetic activity}

Table 4 shows the antiherpetic activity (anti-HSV-1 and antiHSV-2) of genistein solution (solubilized in dimethyl-sulfoxide) and genistein-loaded NE1 and NE3 nanoemulsions. Genistein was significantly $(P<0.05)$ more cytotoxic for Vero cells $\left(\mathrm{CC}_{50}=23.91 \mu \mathrm{g} / \mathrm{mL}\right)$ in comparison with GMK AH1 cells $\left(\mathrm{CC}_{50}=50.36 \mu \mathrm{g} / \mathrm{mL}\right)$. An increase in cytotoxicity was observed when genistein was incorporated into nanoemulsions, especially when GMK AH1 cells were used. As it can be seen, genistein exhibited an $\mathrm{IC}_{50}$ of approximately $13 \mu \mathrm{g} / \mathrm{mL}$ for both viral strains tested (HSV-1, in the KOS strain, and HSV-2, in the strain 333). The incorporation of genistein into formulations (NE1 or $\mathrm{NE3}$ ) reduced the $\mathrm{IC}_{50}$ values for both viral types of viral plaque formation. Blank nanoemulsions (without genistein) showed no activity against HSV-1 and HSV-2 viruses.
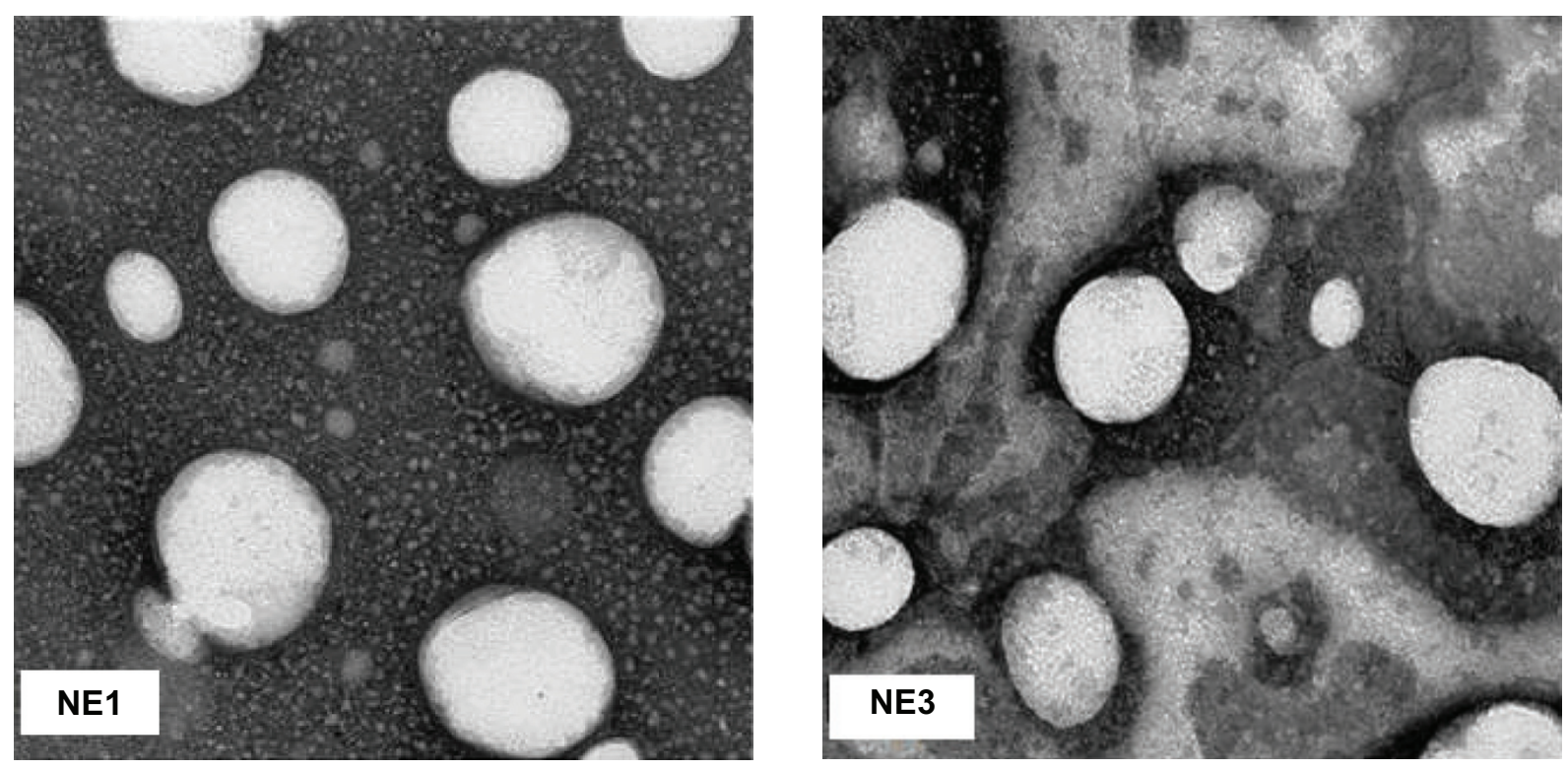

Figure I TEM images of the selected nanoemulsions composed of IM/DSPC/OLA (NEI) and IM/DOPC/OLA (NE3). No differences were detected in the morphology of oil droplets of NEI and NE3.

Note: Scale bar $=200 \mathrm{~nm}$.

Abbreviations: DOPC, dioleylphosphaditylcholine; DSPC, distearoylphosphatidylcholine; IM, isopropyl myristate; NE, nanoemulsion; OLA, oleylamine; TEM, transmission electron microscope. 


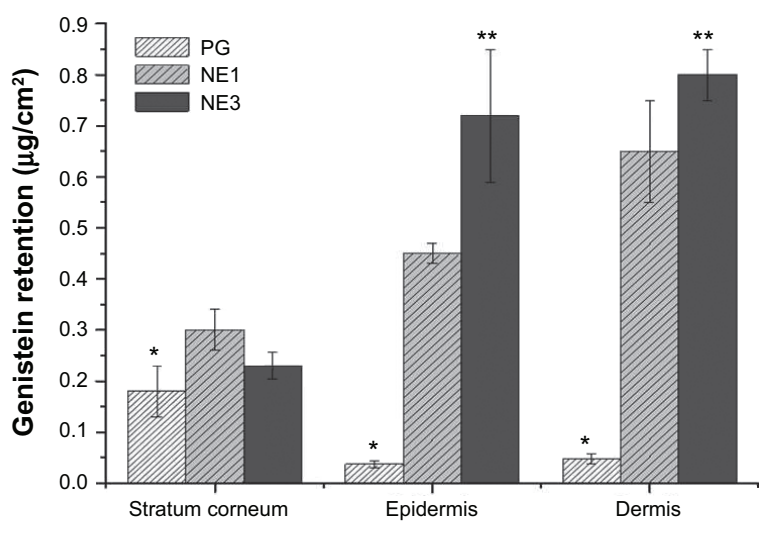

Figure 2 Distribution profile of genistein into porcine ear skin layers after 8 hours of permeation/retention study, from a control solution (PG solution) and NEI and NE3.

Notes: A lower amount of genistein was detected in the stratum corneum from nanoemulsions, with a significantly increased retention of this isoflavone into epidermis and dermis. The values are means \pm SD of five experiments. *Significantly lower $(P<0.05)$ for PG in stratum corneum, epidermis and dermis as compared to NEI and NE3; **significantly higher $(P<0.05)$ for NE3 in epidermis and dermis as compared with PG and NEI.

Abbreviations: PG, propylene glycol; NE, nanoemulsion; SD, standard deviation.

\section{Discussion}

In the present study, we evaluated the effects of lipid components on the properties of nanoemulsions, with the intention of optimizing the composition of the formulations intended for genistein skin delivery. The effects of the oil core, the phospholipid, and the ionic surfactant composition on the different physicochemical properties of nanoemulsions, genistein content, and genistein retention in the skin were evaluated by means of a $2^{3}$ full factorial design. This experimental design enabled all factors to be varied simultaneously, allowing the quantification of the effects caused by independent variables along with the interactions between them. ${ }^{24}$ Main effects alone do not have much meaning when they are involved in significant interactions. These interactions are the key to achieving the optimal conditions.

Among the dependent variables evaluated, the obtained results showed three-way interactions for the droplet size and the polydispersity index of nanoemulsions, as well as for genistein retention in porcine ear skin after 8 hours of permeation/retention kinetics. Such results can be better interpreted using the factorial plots of three-way interactions for these variables (Figure 4).

The IM/DOPC/OLA (NE3) combination led to the lowest droplet size of the nanoemulsions (161 $\pm 6 \mathrm{~nm})$. A smaller droplet size can be related to a greater surface to interact with skin, thus improving the permeation/retention of drugs. ${ }^{30,31}$ However, the polydispersity index of this formulation was
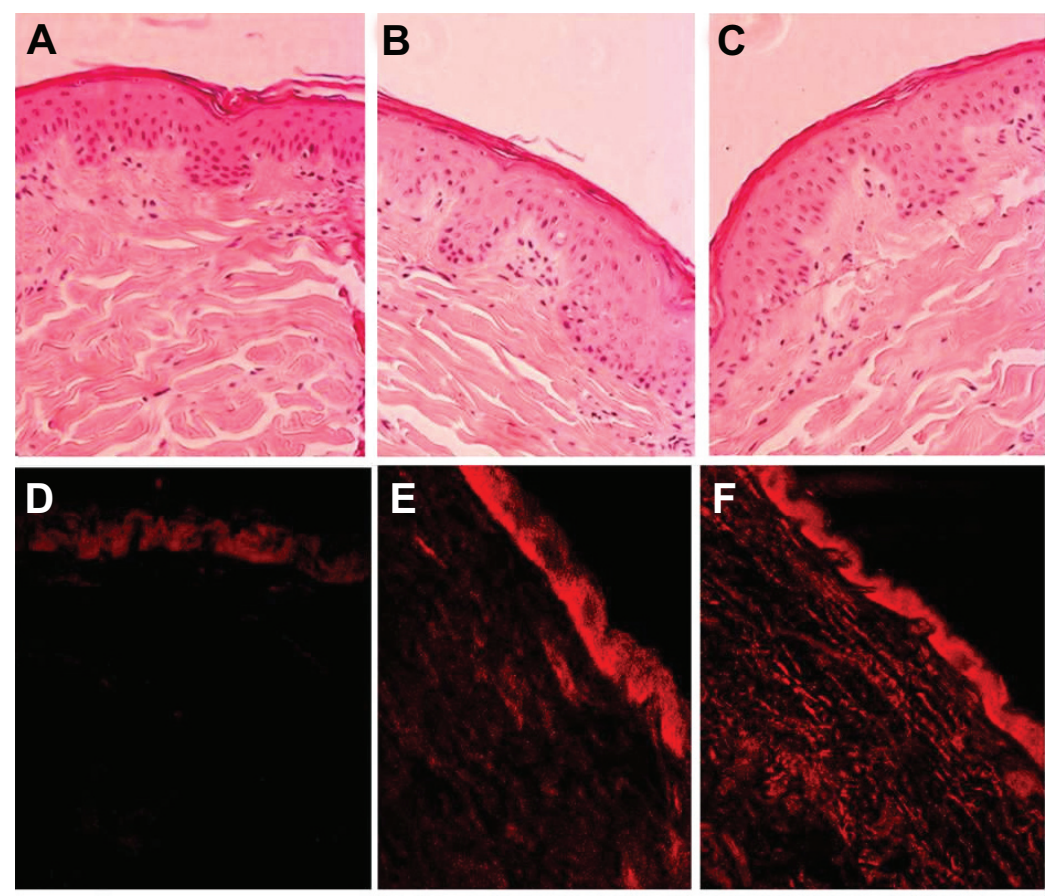

Figure 3 Hematoxylin-/eosin-stained histological (A-C) or fluorescent (D-F) images of full-thickness porcine ear skin treated with a genistein propylene glycol solution (A and $\mathbf{D})$ or with genistein-loaded NEI (B and E) or NE3 (C and F).

Notes: Histological images show no skin damage after treatment with the nanoemulsions. The confocal images revealed that the dye Nile Red was mainly located in stratum corneum when dispersed in propylene glycol. However, the fluorescence was distributed throughout the skin layers when the dye was incorporated into nanoemulsions. Images were obtained after 8 hours of permeation/retention studies using a Franz diffusion cell. Images were obtained at $\times 10$ magnification. Nile Red was used as fluorescent dye in confocal images.

Abbreviation: NE, nanoemulsion. 
Table 4 Cytotoxicity $\left(\mathrm{CC}_{50}\right)$ on Vero and GMK AHI cells and inhibitory effects of HSV-I and HSV-2 replication $\left(\mathrm{IC}_{50}\right)$, respectively, of free-genistein and genistein-loaded nanoemulsions (NEI and NE3)

\begin{tabular}{lllll}
\hline & & Genistein & NEI & NE3 \\
\hline HSV-I & $\mathrm{CC}_{50}(\mu \mathrm{g} / \mathrm{mL})^{*}$ & $23.91 \pm \mathrm{I} .12$ & $16.59 \pm 0.94$ & $17.55 \pm 2.82$ \\
& $\mathrm{IC}_{50}(\mu \mathrm{g} / \mathrm{mL})^{\#}$ & $13.14 \pm \mathrm{I} .26$ & $06.75 \pm 0.13$ & $06.38 \pm 2.63$ \\
$\mathrm{HSV}-2$ & $\mathrm{CC}_{50}(\mu \mathrm{g} / \mathrm{mL})^{*}$ & $50.36 \pm 7.97$ & $19.88 \pm 2.2 \mathrm{I}$ & $2 \mathrm{I} .23 \pm 0.6 \mathrm{I}$ \\
& $\mathrm{IC}_{50}(\mu \mathrm{g} / \mathrm{mL})^{\#}$ & $12.58 \pm \mathrm{I} .62$ & $05.87 \pm 0.85$ & $04.82 \pm 0.62$ \\
\hline
\end{tabular}

Notes: Values represent the mean \pm standard deviations of three independents experiments. *Cytotoxicity was determined by sulforhodamine $B$ assay on Vero and GMK AHI cells. "Antiviral activity was determined by plaque number reduction assay. Abbreviations: $\mathrm{CC}_{50}$, concentration at which cell viability was reduced by $50 \%$; $\mathrm{HSV}$, herpes simplex virus; $\mathrm{IC}_{50}$, concentration that inhibited $50 \%$ of viral plaque number; NE, nanoemulsion; GMK, green monkey kidney.

$0.24 \pm 0.01$, which can be considered a limit value according to the literature. Polydispersity index gives some information about the deviation from the average size, and values up to 0.250 could be acceptable. ${ }^{32}$ From the analysis of variance, the replacement of DOPC (NE3) by DSPC (NE1) showed the lowest polydispersity index $(0.07 \pm 0.02)$. Thus, the ternary mixture of a high transition temperature phospholipid (DSPC) with IM and OLA yielded more homogeneous systems. No marked differences were detected in the oil droplets of these formulations by TEM; the droplet size was in the $200 \mathrm{~nm}$ range, which is in accordance with the photon correlation spectroscopy experiments. Taking into account the physicochemical characterization, NE1 and NE3 were selected for further studies. Similarly, analysis of variance of the data obtained in the experimental design showed three-way interactions for the variable genistein retention in the skin. An overall analysis of the results showed that the use of IM as the oil core instead of $\mathrm{CO}$ led to a significant increase of genistein in the skin. One initial explanation is that IM could be considered a better absorption enhancer than $\mathrm{CO} .{ }^{33,34} \mathrm{In}$ addition, since the solubility of genistein in the IM was significantly lower $(P<0.05)$ than in $\mathrm{CO}$, as demonstrated in this
Size particle $(\mathrm{nm})$

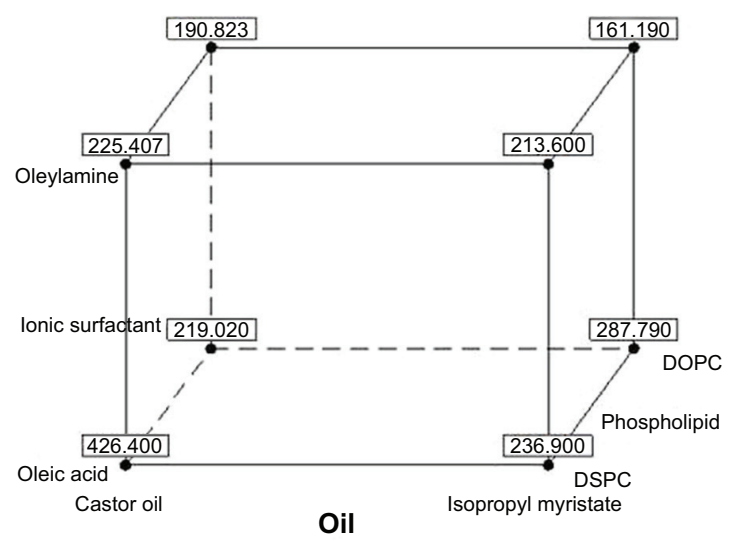

PI

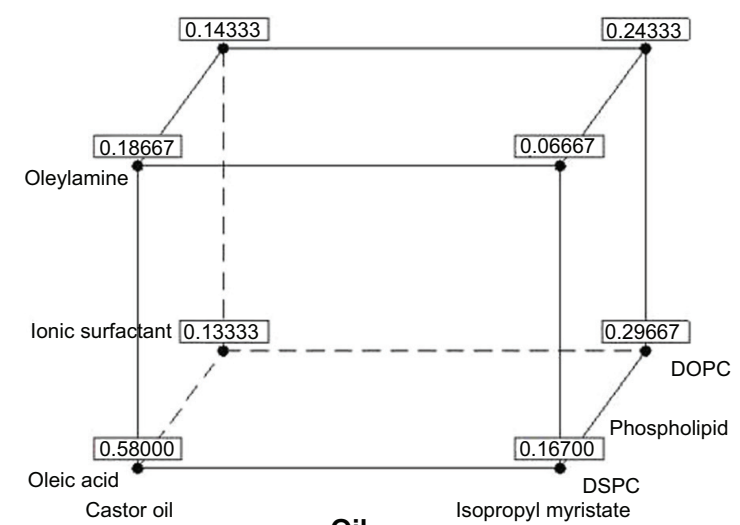

Skin retention $\left(\mu \mathrm{g} / \mathrm{cm}^{2}\right)$

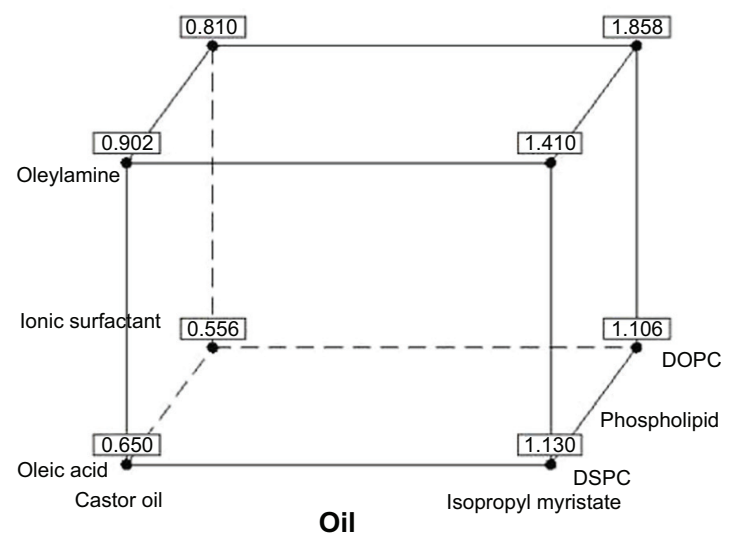

Figure 4 Factorial plots of three-way interactions for droplet size response, polydispersity index response, and genistein retention in the skin.

Notes: The graphical representation shows that the NE3 presented the lowest droplet size and the highest genistein retention in the porcine ear skin. The NEI presented the lowest polydispersity index. The plots were obtained from measured responses.

Abbreviations: DOPC, dioleylphosphaditylcholine; DSPC, distearoylphosphatidylcholine; NE, nanoemulsion; PI, polydispersity index. 
study, a saturation of the vehicle might lead to an increase in the retention of this isoflavone into the skin, whereas the high solubility of genistein in $\mathrm{CO}$ increased the affinity of this isoflavone into the oil core, decreasing the partitioning from the vehicle into the skin. Among the IM-based formulations, the genistein retention in skin was significantly higher $(P<0.05)$ from positively-charged NE3 (composed of IM/ DOPC/OLA), followed by NE1 (composed of IM/DSPC/ OLA). It is well documented that positively-charged colloidal carriers can interact with negatively charged protein residues of epithelial cells, leading to a disturbance in the lipid structure of the stratum corneum, ${ }^{35,36}$ which, in turn, can lead to increased drug permeability. Finally, the formulation composed of IM/DOPC/OLA (NE3) led to a significantly higher amount of genistein retained in the skin when compared with the combination containing DSPC (NE1). This result may be attributed to the more fluid interface of IM/DOPC/ OLA nanoemulsions, due the presence of DOPC, which is in the fluid state and could lead to an increase of partitioning of genistein to the skin.

Regardless of the combination of the lipids used, analysis of variance of the $\zeta$ potential of the nanoemulsions showed only significance for the main effect. In other words, there was no interaction between lipid components over this property. $\zeta$ potential was only influenced by adding charged cosurfactants in the formulation composition. Concerning the selected formulations (NE1 and NE3), the binary mixture of these cosurfactants with DOPC or DSPC did not have a significant effect on this parameter. Since the phosphatidylcholine polar head group of DOPC or DSPC did not exhibit charge (due to the coexistence of the negatively charged phosphate group and the positively charged quaternary ammonium group of choline in the polar head group) at the formulation's final $\mathrm{pH}$, the $\zeta$ potential was only influenced by the presence of OLA. It must be pointed out that the bulk $\mathrm{pH}$ of positively-charged nanoemulsions presented values of approximately 8.5-9.0 due to the presence of the OLA. For these formulations, final $\mathrm{pH}$ was adjusted to 5.0-6.0 to produce theoretically fully ionized OLA molecules at the interface, as previously reported. ${ }^{37,38}$ Furthermore, it was demonstrated that the $\mathrm{pH}$ of the vehicle had a significant effect in the cutaneous retention of genistein, which is higher at a $\mathrm{pH}$ of 6.0, due the nonionic form of genistein in this medium. ${ }^{39}$

For the optimized formulations, the genistein content values were higher than $95 \%(0.96 \pm 0.041$ and $0.95 \pm 0.042$ for NE1 and NE3, respectively), without any difference among them $(P>0.05)$. Since genistein was not detected in the water phase, after separation of a fraction of the water phase on ultrafiltration membranes, this isoflavone seems to be incorporated into the oily phase of nanoemulsions. This result could be attributed to the affinity of this poorly soluble aglycone $(\log \mathrm{P}=3.04)^{40}$ for the lipid components of the inner phase of the nanoemulsions. Regarding the genistein content response, the effect of two-way interaction between the oil (CO or IM) and phospholipid (DSPC or DOPC) factors was observed. Statistical analyses showed that the interaction of CO and DSPC (containing OA or OLA) presented the lowest content of genistein: $0.83 \pm 0.049 \mathrm{mg} / \mathrm{mL}$ (for $\mathrm{NE} 5$ ) and $0.80 \pm 0.061 \mathrm{mg} / \mathrm{mL}$ (for NE6). This result could be related with a decrease of the fluidity of the oil core (in the presence of CO and DSPC) and thus, the solubility of genistein in those formulations.

To have a better insight into the distribution of genistein in the porcine ear skin layers from optimized formulations, stratum corneum, epidermis, and dermis were separated and the amount of this isoflavone determined by HPLC. A higher amount of genistein was detected in the deep layers (epidermis and dermis) when isoflavone was incorporated into nanoemulsions, indicating that the positively-charged optimized formulations were able to overcome the barrier property of the outermost layer of the skin. The skin retention of genistein from other colloidal carriers has been described elsewhere. ${ }^{41-43}$ Conversely, the skin retention of genistein from the propylene glycol control solution was higher in the stratum corneum, which demonstrates that skin penetration is hampered by the barrier effect of the stratum corneum. These results were illustrated by the confocal images. A higher fluorescence intensity was detected in the deep layers of porcine ear skin (without a deleterious effect on the skin, according to histological photomicrographs) when compared with images obtained with a propylene glycol solution, in which Nile Red seemed to be located mainly in the upper skin layers.

Finally, our results clearly showed the inhibition of HSV-1 and HSV-2 replication by genistein, which follows in line with data previously reported by Yura et al. ${ }^{10}$ Interestingly, the incorporation of genistein into the optimized nanoemulsions (NE1 and NE3) decreased the $\mathrm{IC}_{50}$ of the viral plaque formation, against both HSV-1 and HSV-2. This result suggests that the nanoemulsions tested could enhance intracellular genistein uptake. They most probably took advantage from the destabilization of the cell membrane due to the positive charges of the nanoemulsions, which probably increased membrane permeability and allowed the genistein molecules to enter the cells more efficiently. ${ }^{44}$ For instance, the formulation composed of IM/DOPC/OLA (NE3) showed an $\mathrm{IC}_{50}$ up to 2.6-fold lower than free-genistein in HSV-2. This formulation exhibited a selectivity index (that is the 
ratio between $\mathrm{CC}_{50}$ and $\mathrm{IC}_{50}$ ) higher than 4 , which can be considered promising for candidates as antiviral agents. ${ }^{45}$ The antiherpetic activity of genistein has been related to the protein-tyrosine phosphorylation, which is involved in the regulation of cell growth and in receptor-mediated signal transduction; ${ }^{9}$ however, the mechanism needs to be fully elucidated.

\section{Conclusion}

The factorial design allowed us to select the combinations of IM, OLA, DSPC, or DOPC as the best inner phases for stable nanoemulsions with higher potential for increasing skin retention of genistein, showing the effect of positively charged nanoemulsions on these properties. A significant increase in the genistein content was detected into viable skin layers (epidermis and dermis) when this isoflavone was incorporated into nanoemulsions, without visible skin damage as it was visualized in the histological images. These results were supported by confocal laser scanning microscopy experiments. Finally, such formulations exhibited in vitro antiherpetic activity against HSV-1 (strain KOS) and HSV-2 (strain 333). Taken together, the results showed that the genistein-loaded nanoemulsions developed are promising for antiherpes treatment.

\section{Acknowledgments}

This work was supported by the Brazilian Federal Agency for Support and Evaluation of Graduate Education (CAPES), Rede Nanobiotec-Brazil (grant number 902/2009) and the State Foundation for Research Support (FAPERGS) PRONEM (grant number 11/2206-7). DA wishes to thank CAPES for her scholarship.

\section{Disclosure}

The authors report no conflicts of interest in this work.

\section{References}

1. Brady RC, Bernstein DI. Treatment of herpes simplex virus infections. Antiviral Res. 2004;61(2):73-81.

2. Simmons A. Clinical manifestations and treatment considerations of herpes simplex virus infection. J Infect Dis. 2002;186 Suppl 1:S71-S77.

3. Mundinger TA, Efferth T. Herpes simplex virus: Drug resistance and new treatment options using natural products (Review). Mol Med Rep. 2008;1(5):611-616.

4. Field HJ. Herpes simplex virus antiviral drug resistance-current trends and future prospects. J Clin Virol. 2001;21(3):261-269.

5. Chiang LC, Chiang W, Chang MY, Ng LT, Lin CC. Antiviral activity of Plantago major extracts and related compounds in vitro. Antiviral Res. 2002;55(1):53-62.

6. Zhong MG, Xiang YF, Qiu XX, Liu Z, Kitazato K, Wang YF. Natural products as a source of anti-herpes simplex virus agents. RSC Advances. 2013;3:313-328.
7. Lyu SY, Rhim JY, Park WB. Antiherpetic activities of flavonoids against herpes simplex virus type 1 (HSV-1) and type 2 (HSV-2) in vitro. Arch Pharm Res. 2005;28(11):1293-1301.

8. Akiyama T, Ishida J, Nakagawa S, et al. Genistein, a specific inhibitor of tyrosine-specific protein kinases. J Biol Chem. 1987;262(12):5592-5595.

9. Andres A, Donovan SM, Kuhlenschmidt MS. Soy isoflavones and virus infections. J Nutr Biochem. 2009;20(8):563-569.

10. Yura Y, Yoshida H, Sato M. Inhibition of herpes simplex virus replication by genistein, an inhibitor of protein-tyrosine kinase. Arch Virol. 1993;132(3-4):451-461.

11. Hukkanen V, Mikola H, Nykänen M, Syrjänen S. Herpes simplex virus type 1 infection has two separate modes of spread in three-dimensional keratinocyte culture. J Gen Virol. 1999;80(Pt 8):2149-2155.

12. Elias PM, Cooper ER, Korc A, Brown BE. Percutaneous transport in relation to stratum corneum structure and lipid composition. $J$ Invest Dermatol. 1981;76(4):297-301.

13. Swartzendruber DC, Wertz PW, Kitko DJ, Madison KC, Downing DT. Molecular models of the intercellular lipid lamellae in mammalian stratum corneum. J Invest Dermatol. 1989;92(2):251-257.

14. Kaplun-Frischoff Y, Touitou E. Testosterone skin permeation enhancement by menthol through formation of eutectic with drug and interaction with skin lipids. J Pharm Sci. 1997;86(12):1394-1399.

15. Williams AC, Barry BW. Penetration enhancers. Adv Drug Deliv Rev. 2004;56(5):603-618.

16. Barel AO, Paye M, Maibach HI. Handbook of Cosmetic Science and Technology. 3rd ed. New York, NY: Marcel Dekker; 2009.

17. Kumar D, Aqil M, Rizwan M, Sultana Y, Ali M. Investigation of a nanoemulsion as vehicle for transdermal delivery of amlodipine. Pharmazie. 2009;64(2):80-85.

18. Harwansh RK, Patra KC, Pareta SK, Singh J, Rahman MA. Nanoemulsions as vehicles for transdermal delivery of glycyrrhizin. Braz J Pharm Sci. 2011;47(4):769-778.

19. Barakat N, Fouad E, Elmedany A. Enhancement of skin permeation and anti-inflammatory effect of indomethacin using nanoemulsuion. Lett Drug Des Discov. 2012;9(4):436-446.

20. Hoeller S, Sperger A, Valenta C. Lecithin based nanoemulsions: A comparative study of the influence of non-ionic surfactants and the cationic phytosphingosine on physicochemical behaviour and skin permeation. Int J Pharm. 2009;370(1-2):181-186.

21. Gulbake A, Jain A, Jain S. Development of nanostructured lipid carrier as potential sun protectant. Nanoscience and Nanotechnology-Asia. 2012;2(2):210-216.

22. Fernández-Campos F, Clares Naveros B, López Serrano O, Alonso Merino C, Calpena Campmany AC. Evaluation of novel nystatin nanoemulsion for skin candidosis infections. Mycoses. 2013;56(1):70-81.

23. Morganti P, Ruocco E, Wolf R, Ruocco V. Percutaneous absorption and delivery systems. Clin Dermatol. 2001;19(4):489-501.

24. Montgomery DC. Design and Analysis of Experiments. 3rd ed. Somerset, NJ: John Wiley \& Sons Inc; 1991.

25. Silva AP, Nunes BR, De Oliveira MC, et al. Development of topical nanoemulsions containing the isoflavone genistein. Pharmazie. 2009; 64(1):32-35.

26. de Vargas BA, Argenta DF, Borghetti G, Koester LS, Bassani VL, Teixeira HF. Validation of an LC method to determine skin retention profile of genistein from nanoemulsions incorporated in hydrogels. J Chromatogr Sci. 2012;50(2):114-118.

27. Burleson RC, Chambers TM, Wiedbrauk DL. Virology: A Laboratory Manual. San Diego, CA: Academic; 1992.

28. Vichai V, Kirtikara K. Sulforhodamine B colorimetric assay for cytotoxicity screening. Nat Protoc. 2006;1(3):1112-1116.

29. Silva IT, Costa GM, Stoco PH, Schenkel EP, Reginatto FH, Simões CM. In vitro antiherpes effects of a C-glycosylflavonoid-enriched fraction of Cecropia glaziovii Sneth. Lett Appl Microbiol. 2010;51(2):143-148.

30. Abolmaali SS, Tamaddon AM, Farvadi FS, Daneshamuz S, Moghimi H. Pharmaceutical nanoemulsions and their potential topical and transdermal applications. Iranian Journal of Pharmaceutical Sciences. 2011; $7(3): 139-150$ 
31. Mitri K, Shegokar R, Gohla S, Anselmi C, Müller RH. Lipid nanocarriers for dermal delivery of lutein: preparation, characterization, stability and performance. Int J Pharm. 2011;414(1-2):267-275.

32. Müller RH, Schmidt S, Buttle I, Akkar A, Schmitt J, Brömer S. SolEmuls-novel technology for the formulation of i.v. emulsions with poorly soluble drugs. Int J Pharm. 2004;269(2):293-302.

33. Goldberg-Cettina M, Liu P, Nightingale J, Kurihara-Bergstrom T. Enhanced transdermal delivery of estradiol in vitro using binary vehicles of isopropyl myristate and short-chain alkanols. Int J Pharm. 1995; 114(2):237-245.

34. Santos P, Watkinson AC, Hadgraft J, Lane ME. Influence of penetration enhancer on drug permeation from volatile formulations. Int J Pharm. 2012;439(1-2):260-268.

35. Rojanasakul Y, Wang LY, Bhat M, Glover DD, Malanga CJ, Ma JK. The transport barrier of epithelia: a comparative study on membrane permeability and charge selectivity in the rabbit. Pharm Res. 1992;9(8): 1029-1034.

36. Eskandar NG, Simovic S, Prestidge CA. Mechanistic insight into the dermal delivery from nanoparticle-coated submicron $\mathrm{O} / \mathrm{W}$ emulsions. J Pharm Sci. 2010;99(2):890-904.

37. Rabinovich-Guilatt L, Couvreur P, Lambert G, Goldstein D, Benita S, Dubernet C. Extensive surface studies help to analyse zeta potential data: the case of cationic emulsions. Chem Phys Lipids. 2004;131(1):1-13.

38. Martini E, Fattal E, de Oliveira MC, Teixeira H. Effect of cationic lipid composition on properties of oligonucleotide/emulsion complexes: Physico-chemical and release studies. Int J Pharm. 2008;352(1-2): 280-286.
39. Huang ZR, Hung CF, Lin YK, Fang JY. In vitro and in vivo evaluation of topical delivery and potential dermal use of soy isoflavones genistein and daidzein. Int J Pharm. 2008;364(1):36-44.

40. Rothwell JA, Day AJ, Morgan MR. Experimental determination of octanol-water partition coefficients of quercetin and related flavonoids. J Agric Food Chem. 2005;53(11):4355-4360.

41. Kim SY, Na YJ, Kim D, et al. Development of estimation methods of skin oxidation and evaluation of anti-oxidative effects of genistein in topical formulations. Korean J Physiol Pharmacol. 2012;16(3):205-209.

42. Kitagawa S, Inoue K, Teraoka R, Morita SY. Enhanced skin delivery of genistein and other two isoflavones by microemulsion and prevention against UV irradiation-induced erythema formation. Chem Pharm Bull (Tokyo). 2010;58(3):398-401.

43. Zampieri AL, Ferreira FS, Resende EC, et al. Biodegradable polymeric nanocapsules based on poly(DL-lactide) for genistein topical delivery: obtention, characterization and skin permeation studies. J Biomed Nanotechnol. 2013;9(3):527-534.

44. Rehman $\mathrm{Zu}$, Zuhorn IS, Hoekstra D. How cationic lipids transfer nucleic acids into cells and across cellular membranes: recent advances. J Control Release. 2013;166(1):46-56.

45. Amoros M, Simões CM, Girre L, Sauvager F, Cormier M. Synergistic effect of flavones and flavonols against herpes simplex virus type 1 in cell culture. Comparison with the antiviral activity of propolis. $J$ Nat Prod. 1992;55(12):1732-1740.
International Journal of Nanomedicine

\section{Publish your work in this journal}

The International Journal of Nanomedicine is an international, peerreviewed journal focusing on the application of nanotechnology in diagnostics, therapeutics, and drug delivery systems throughout the biomedical field. This journal is indexed on PubMed Central, MedLine, CAS, SciSearch $®$, Current Contents $\AA /$ Clinical Medicine,

\section{Dovepress}

Journal Citation Reports/Science Edition, EMBase, Scopus and the Elsevier Bibliographic databases. The manuscript management system is completely online and includes a very quick and fair peer-review system, which is all easy to use. Visit http://www.dovepress.com/ testimonials.php to read real quotes from published authors. 